Int. J. Dev. Biol. 49: 243-250 (2005)

doi: $10.1387 / \mathrm{ijdb} .041957 \mathrm{mt}$

\title{
Embryonic development of the human hematopoietic system
}

\author{
MANUELA TAVIAN*,1 and BRUNO PÉAULT ${ }^{1,2}$ \\ ${ }^{1}$ INSERM U506, Hôpital Paul Brousse, Villejuif, France and ${ }^{2}$ Department of Pediatrics, Rangos Research Center, \\ Children's Hospital, Pittsburgh, PA, USA
}

\begin{abstract}
Human hematopoiesis is initiated in the yolk sac during the third week of development. At the same time the capacity to produce blood cells also arises in the embryo, within the splanchnopleura, but this potential is not expressed before day 27 , when clustered hematopoietic stem cells emerge from the ventral wall of the aorta and vitelline artery. Budding of hematopoietic cells from vessel walls reflects the re-differentiation of local endothelial cells, which are likely derived from angio-hematopoietic mesodermal ancestors emigrated from the splanchnopleura. Yolk sac-derived stem cells are limited to myelo-erythroid development, whereas those born in the embryo are, in addition, lymphopoietic and therefore represent the first multi-potent, adulttype blood progenitors that appear in human ontogeny, preceding shortly the onset of liver hematopoiesis. These results allowed the establishment of a novel hierarchy of blood-forming tissues in human development and induced an in depth reconsideration of the very origin of definitive human hematopoiesis. These results also fully corroborate the outcome of experiments performed in parallel in avian and mouse embryos and point to the conservation in all higher vertebrates of an ancestral route of blood cell production via embryonic vessel walls.
\end{abstract}

KEY WORDS: human embryo, stem cell, hematopoiesis, lymphocyte, endothelium

\section{Introduction}

In adult mammals, hematopoiesis normally occurs in the bone marrow, which supports simultaneously, within distinct cellular environments, the life-long maintenance of stem cells and the regulated production of end-stage lymphoid, myeloid and erythroid cells. Hematopoietic stem cells (HSC) encountered in the adult bone marrow arise by replication and amplification of a stock of HSC that emerged early in ontogenesis, when the bone marrow had not yet formed.

Indeed, a succession of organs sustains blood cell production during the embryogenesis of vertebrates. In vertebrates, the earliest hematopoietic activity is indicated by the appearance of blood islands in the mesoderm of the extraembryonic yolk sac. The yolk sac, which sustains principally primitive erythropoiesis, is later relayed by the liver and spleen, the role of which in blood cell production varies along phylogeny and eventually by the thymus and bone marrow, where post-natal definitive hematopoiesis becomes stabilized. Blood cell tracing along embryonic development was pioneered in parabiotic sexmismatched chicken embryos (Moore and Owen, 1967) and was later much refined and exploited in the quail-chicken chimera system (reviewed in Le Douarin et al., 1984). These experiments revealed that the development of intra-embryonic blood-forming tissues depends on the colonization of their rudiments by bloodborne hematopoietic progenitor cells. This observation first set the basis for the prevailing idea that the YS be the unique provider of HSC, since no intrinsic hematopoietic potential could be attributed to any other tissue inside the embryo (Moore and Owen, 1967). According to this theory, development of the blood system in vertebrates was long described as a monophyletic process with a unique organ of hematopoietic cell emergence - the yolk sac colonizing other organs: first the liver, then the thymus, spleen and finally the bone marrow (Moore and Metcalf, 1970).

The scarcity of available human tissues at early embryonic stages as well as the very narrow range of assays in which human cells could be analyzed have hampered the study of the emerging human hematopoietic system, which for a long time only reposed on incidental morphologic observations (Rosenberg, 1969). This situation changed at the end of the 1980ies with the advent of a rapidly expanding array of markers for human hematopoietic cells, the development of long-term human HSC cultures and the successful engraftment of human hematopoietic cells in immune-

Abbreviations used in this paper: AGM, embryonic region comprising the aorta, genital ridges andmesonephros; HPP-CFC, high-proliferative potential colony forming cell; HSC, hematopoietic stem cell. 
deficient mice (reviewed in Peault et al., 1992; Peault, 1995; Peault et al., 1992; Vormoor et al., 1995). Such technical improvements permitted to get novel insights into human developmental hematology, including the identification of human HSCs at pre- and post-natal stages (Baum et al., 1992, Charbord et al., 1996a, Kyoizumi et al., 1993, Peault et al., 1991, Uchida et al., 1997). At the same period, access to earlier stages of human gestation turned easier because the anti-progestative compound RU486 became routinely used to electively terminate early pregnancies in France. Our laboratory at the Institut d'Embryologie then launched a program aimed at investigating incipient hematopoiesis in the first two months of human development.

As detailed elsewhere in this volume, the Institut d'Embryologie du CNRS et du College de France has made major contributions to developmental hematology and immunology. By creating multiple tissue combinations in quail/chicken chimaeras, N. Le Douarin and her team have deciphered the principle and chronology of HSC seeding to the embryonic thymus, bursa of Fabricius and bone marrow and ascertained the role of thymic epithelium in the induction of self tissue tolerance (reviewed in Le Douarin et al., 1984). One of us participated in these studies by defining molecular markers for avian hematopoietic cells that were used to characterize the ontogeny of blood cell lineages in normal embryos and quail-chicken chimeras (Guillemot et al., 1986, Peault, 1987, Peault etal., 1983). On the other hand, the group led by Françoise Dieterlen in the same Institute has challenged the monophyletic theory of blood cell development by discovering that stem cells emerging inside the embryo proper and not in the yolk sac, are at the origin of definitive hematopoiesis in birds (Dieterlen-Lievre, 1975). Similar conclusions were reached by the same group regarding the origin of HSC in the mouse embryo (Cumano et al., 1996). Both groups at the Institut d'Embryologie have also pioneered the study of vascular development in the avian embryo, making use of original markers of the hemangioblastic cell lineage (Pardanaud et al., 1987, Peault, 1987).

We herein describe how we have, in this modern developmental hematology context, revisited the ontogeny of the human hematopoietic system. Our observations have pointed to the existence of a conserved scheme of hematopoietic stem cell emergence in vertebrate embryos (Tavian et al., 1996). The intraembryonic site of HSC generation we have identified represents also an original model whereby the induction and regulation of human hematopoiesis can be approached.

\section{Extra-embryonic generation of hematopoietic cells}

As is the case in other higher vertebrates, human hematopoiesis starts outside the embryo, in the yolk sac, then proceeds transiently in the liver before getting stabilized until adult life in the bone marrow. Only T cells are produced in the same tissue at embryonic, fetal and post-natal stages.

\section{The yolk sac}

In higher vertebrates, a network of mesoderm cell aggregates at the origin of both vascular and hematopoietic systems develops shortly after gastrulation in the extra-embryonic area. In these initially homogeneous solid clusters, peripheral cells acquire the morphology and markers of endothelial cells, while internal ones simultaneously disappear to open the first vessel lumens. Clumps of primitive mesodermal cells remaining adherent to the newly formed vascular endothelium - called blood islands - are at the origin of extra-embryonic hematopoiesis (Maximov, 1909, Sabin, 1920). Since both endothelial and hematopoietic cells develop from the same clusters of mesoderm, the existence of an ancestral precursor common to both lineages was postulated: the angioblast (Sabin, 1920), later renamed hemangioblast (Murray, 1932, Sabin, 1920). This term (that was initially coined to designate a group of blood- and vessel-forming mesoderm cells and not a single cell), fell into oblivion until the existence of such angiohematopoietic stem cells was supported experimentally (Choi et al., 1998, Eichmann et al., 1997, Peault, 1987). The mesoderm of the human yolk sac has been shown to exhibit localized thickenings that probably represent the primordial blood islands, at about 16 days of development (Luckett, 1978). This is too early a stage to be accessed from elective pregnancy interruptions. Yet, occasional histological investigations have indicated that the human yolk sac produces mostly erythroid cells (Bloom and Bartelmez, 1940). The occasional presence of macrophages and primitive megakaryocytes has been also described (Fukuda, 1973). Although studies on hematopoietic cell emergence at these early stages still remain scarce, our own observations from day 19 of development have suggested that the sequence described in animal embryos also applies to the human yolk sac (Cortes et al., 1999, Tavian et al., 1999). Mesoderm-derived clusters of primitive hematopoietic cells - or blood islands - develop in close association with the endothelium of emerging yolk sac blood vessels. The co-expression of the CD34 surface molecule by hematopoietic cells within solid blood islands and by adjacent developing endothelial cells is consistent with the existence of a common hemangioblast precursor for blood and endothelial cell lineages (Tavian et al., 1999). It remains to be determined, though, whether CD34 marks such a putative hemangioblast in the undifferentiated human yolk sac mesoderm prior to the onset of vasculogenesis. In this respect, CD34 expression in the early human yolk sac is reminiscent of that of MB1 (aka QH1) in the quail yolk sac. Similar to CD34 in man, the MB1 glycoprotein is expressed at the surface of quail endothelial and hematopoietic cells throughout embryonic and post-hatching life (Peault etal., 1983). However, MB1 is first expressed in the yolk sac by emerging endothelial cells rather than by earlier, undifferentiated hemangioblastic mesoderm (Peault, 1987). This may suggest that yolk sac endothelial cells are the forerunners of extra-embryonic hematopoietic cells, as is the case for intraembryonic hematopoiesis (see below). Earlier authors already hypothesized the existence of blood-forming endothelial cells in the avian yolk sac (Sabin, 1920).

The first functional study of human yolk sac hematopoiesis showed the presence of several generations of clonogenic progenitors at 4.5-weeks of development, including pluripotent (CFU GEMM), early (BFU E), or late (CFU E) erythroid and granulo-macrophage (CFU-GM) progenitors (Migliaccio et al., 1986). The frequency of these progenitors drops dramatically thereafter, to disappear definitively after 6 weeks of gestation. These observations were confirmed by another group, which documented the presence of both erythroid and granulopoietic progenitors in the yolk sac as early as day 25 of development (Dommergues et al., 1992, Huyhn et al., 1995). However, these authors reported that the frequency of these precursors remains almost constant between days 35 and 50 . Since all the assays were 
carried out at stages when blood already circulates between the yolk sac and embryo, these discrepancies can reflect the presence in the yolk sac of precursor cells of extrinsic origin. In any case, these reports all agreed on the total disappearance of yolk sac hematopoiesis after the $60^{\text {th }}$ day of development. Hence, the relative duration of yolk sac hematopoiesis during human gestation is much shorter than in birds and rodents.

\section{Onset of blood circulation}

The above-described observations have documented the hematopoietic potential of yolk sac-derived precursor cells in culture, which does not necessarily reflect the differentiation process that takes place during normal development. Blood cells produced in the yolk sac are predominantly nucleated erythrocytes, which synthesize embryonic hemoglobin $(\zeta \varepsilon)$. This first wave of erythrocyte production in the yolk sac is known as primitive, in contrast with the production of definitive erythrocytes, which takes place later in the liver. Primitive erythrocytes, already expressing the surface molecule glycophorin A, have also been detected in the cardiac cavity as early as the 3-somite stage (21 days) (Tavian et al., 1999). Such observations indicate that vascular connections between the yolk sac and embryo are initiated at this stage, no blood cells being ever found inside the embryo proper at day 19 of development (MT, unpublished observations).

\section{Colonization of embryonic hematopoietic tissues}

The onset of circulation, which occurs in concomitance with the beginning of cardiac beating, allows yolk-sac derived blood cells to enter embryonic tissues. The first organ to be colonized is the liver, which remains the main blood-forming tissue in the embryo before the initiation of marrow hematopoiesis.

\section{The liver}

The liver develops from an endodermal diverticulum of the foregut, at the duodenal level, that migrates rostrally and penetrates the mesodermal septum transversum. These two tissues contribute hepatic parenchymal cords (hepatocytes) and vascular sinuses, respectively. In the human embryo the hepatic plate has been identified as an endodermal thickening at the rostral intestinal end, caudal to the heart at around 22 days of gestation (10-somite stage) (Severn, 1971). The assumption that the human embryonic liver rudiment is not able to produce blood cell progenitors, as previously shown in the mouse (Moore and Metcalf, 1970), but rather receives hematopoietic cells of yolk sac origin, which then proliferate and differentiate, was first suggested by Kelemen and coll. in 1979.

\section{Yolk sac $\rightarrow$ liver transition}

The transition from yolk sac to liver hematopoiesis was studied by analysis of the hemoglobin synthesis program and in vitro clonogenic assays. The embryonic $\rightarrow$ fetal globin switches (i.e. $\zeta$ $\rightarrow \alpha$ and $\varepsilon \rightarrow \gamma$ ) occurring in the liver reflect the transition from primitive nucleated (megaloblasts) to definitive enucleated (macrocytes) erythrocytes (Peschle et al., 1984). Primitive megaloblasts present in the early hepatic rudiment from week 4.5 to week 5 decrease rapidly in number, to be replaced simultaneously by definitive macrocytes. This phenomenon can imply a monoclonal model, where a single stem-cell pool would first give rise to primitive yolk sac erythropoiesis, then migrate to the liver to generate the definitive erythroblast lineage (Peschle et al., 1985). Such a conclusion was also suggested by the analysis of in vitro colony-forming cells (CFCs) identified in yolk sac, liver and circulating blood cultures. In the fifth week, the yolk sac BFU-E pool undergoes a dramatic reduction, while these progenitors become rapidly detectable in the bloodstream and liver parenchyma (Migliaccio et al., 1986). Therefore, stem cells and already committed progenitors would migrate from the YS to the liver at around 5 weeks of gestation. At the end of the first trimester and onwards, more primitive progenitors, CFU-GEMM and high-proliferative potential colony-forming cells (HPP-CFC) have also been detected in the liver (Hann et al., 1983). In contrast, our recent work documents the appearance of hematopoietic cells inside the hepatic rudiment at earlier stages of development. At the 12-somite stage (23 days), we detected rare, scattered CD34-negative erythro-myeloid cells within developing hepatic sinusoids, suggesting that a first, previously unsuspected hepatic colonization occurs at this stage. The first $\mathrm{CD} 34^{+}$hematopoietic progenitors could be recognized in the liver anlage from day 30 only, the stage at which we propose that a second hepatic colonization takes place. The fact that this novel wave of hematopoietic cells entering the liver at three weeks of human development be composed solely of late-stage progenitors
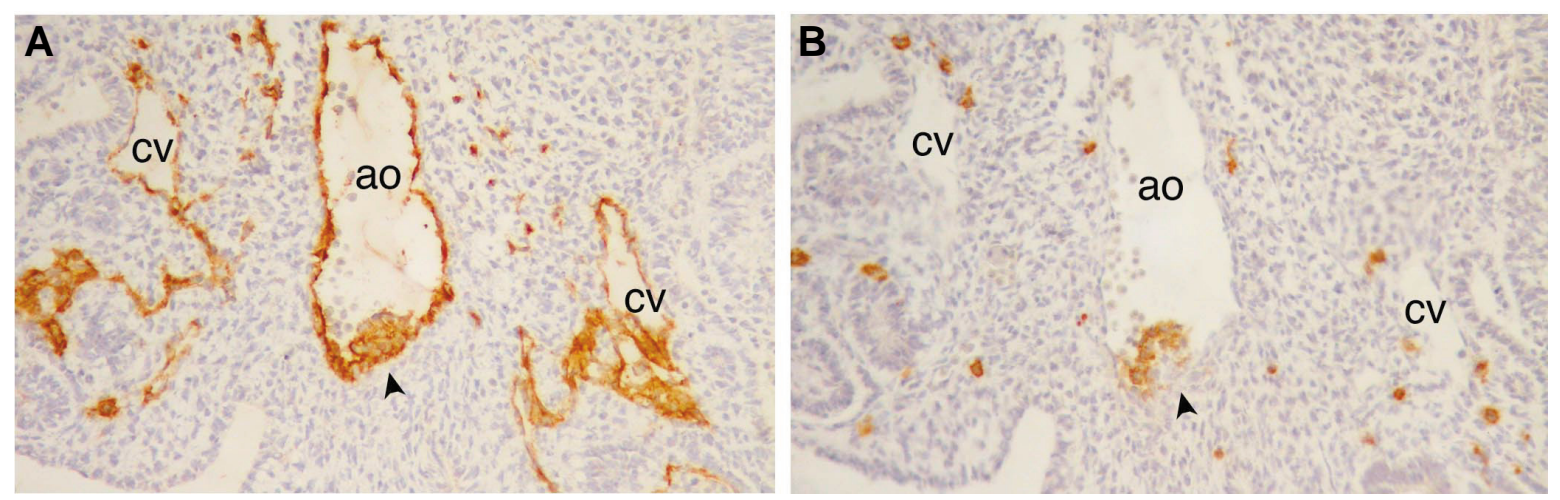

Fig. 1. Hematopoietic stem cell clusters inside human embryonic arteries. Transverse sections of a 32-day human embryo stained with the antiCD34 (A) and anti CD45 (B) antibodies. Arrows indicate the clusters of hematopoietic stem cells adhering to the ventral aspect of the aorta (a). Cardinal vein (cv). 
A

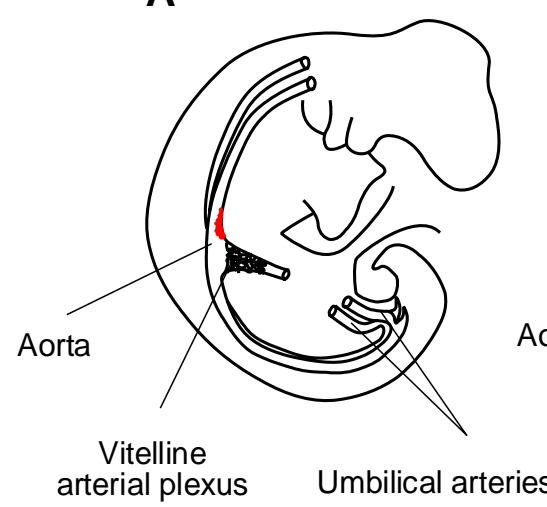

B

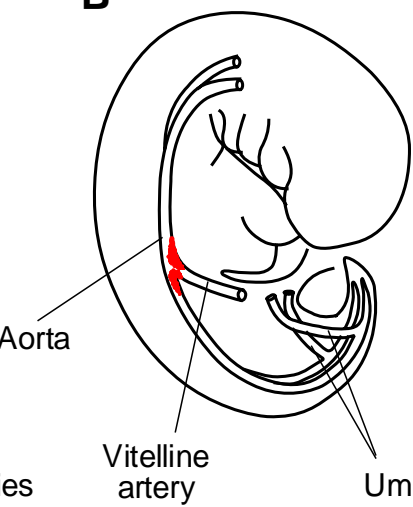

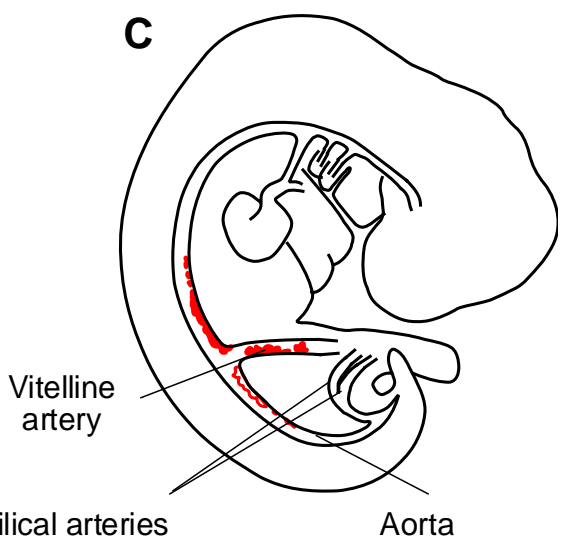

Fig. 2. Sequence of hematopoietic stem cell cluster emergence within the human embryo. (A) Starting from 27 days of development, scattered groups of a few hematopoietic stem cells appear, adhering to the aortic endothelium in the pre-umbilical region. Groups of 2-3 cells are also often detected in a more rostral region, where the aorta is still bifurcated. (B) From day 30 of development the hematopoietic cell clusters increase in size and groups of cells are also encountered at the bifurcation of the vitelline artery, always associated with the ventral aspect of the vascular endothelium. The size of hematopoietic progenitor clusters attains several hundreds of cells at 36 days of development (C). At subsequent stages stem cell clusters undergo gradual decrease till day 40 , the latest at which they could be detected.

was confirmed by cell culture experiments. Indeed, it is only after day 32 of development that the liver contains primitive precursors able to establish long-term hematopoiesis in vitro (Tavian et al., 1999).

\section{Bone marrow}

The bone marrow, the main blood-forming tissue in the adult mammal, is also the last one that develops in ontogenesis, when hematopoiesis is already extinct in the yolk sac, transiently proceeding in the liver and actively developing in the thymus. Studies on the early ontogenesis of the mammalian bone marrow remain scarce. By virtue of an immuno-histochemical approach, we have previously explored the establishment of hematopoiesis within human medullary cavities (Charbord et al., 1996b). Marrow
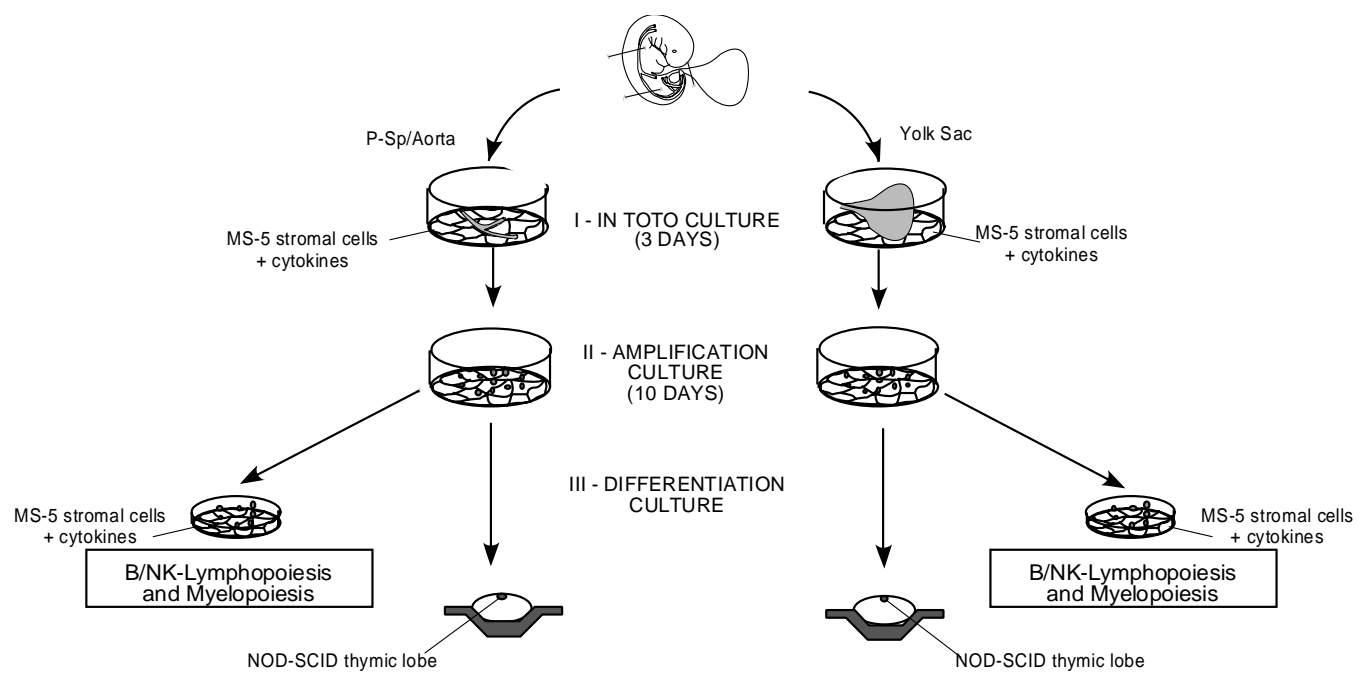

T-Lymphopoiesis

Fig. 3. Scheme of in vitro assays used to detect myeloid-, NK-, B-and T-cell potentialities in the early human embryo. hematopoiesis starts during the $11^{\text {th }}$ week of human development in specialized mesodermal structures - or primary logettes constituted by a loose network of mesenchymal cells supported by dense fibrillar material and surrounding a central artery. The earliest blood cells that differentiate within the bone marrow are $\mathrm{CD}^{+} 5^{+}$myeloid cells, closely followed by glycophorin $\mathrm{A}^{+}$ erythrocytes. Surprisingly, this process is not preceded by an influx of CD34+ hematopoietic precursor cells (Charbord et al., 1996b). Of additional note, the primary logettes, where incipient marrow hematopoiesis protrudes inside medullary sinuses, hence are located at the farthest possible distance from ossifying cartilage trabeculae, at the surface of which lie the bone marrow osteoblasts. This is puzzling inasmuch as osteoblasts have recently been shown to represent a key component of the hematopoiesissupporting bone marrow stroma and, notably, to participate in the niche that nurses hematopoietic stem cells (Zhang et al., 2003). We can, however, possibly reconcile these diverging observations in light of a parallel study we have performed on fetal mouse bone marrow (Blazsek et al., 2000). Although hematopoietic cells colonize the mouse marrow rudiment from about day 15 of development, these cells appear to be only late-stage committed progenitors. Conversely, it is only at 4-5 days after birth that genuine HSCs, capable of seeding longterm hematopoietic cultures, emerge within the mouse bone marrow.

It therefore appears that in the fetal bone marrow (and possibly also, to some extent, in the 
embryonic liver), a first line of rapidly developing hematopoiesis becomes established early in development by committed progenitor cells for accelerated procurement of vital myeloerythroid blood cells. True HSC, as well as their supporting stromal environment, would settle only later and sustain hematopoiesis in the long run (Blazsek et al., 2000).

\section{Hematopoietic cells also emerge inside the human embryo}

As previously introduced, all the observations described above may reflect a classic scheme for the development of the human hematopoietic system, along which all blood cells derive from precursors that were generated in the yolk sac but persist until adult life. However, this notion of a monophyletic development of the human blood system was challenged by our observation that an additional wave of HSC generation takes place within the human embryo between the differentiation of yolk sac blood islands and the colonization of the liver.

\section{Embryonic arterial cell clusters}

We initially observed the consistent presence of densely packed hematopoietic cells adhering firmly to the ventral endothelium of human embryonic arteries (Tavian et al., 1996) (Fig. 1). These elements, detected from 27 days of development as small groups of 2-3 cells in the more rostral, duplicated section of the aorta, rapidly proliferate to constitute, at day 35 , clusters of several thousands of cells that extend toward the umbilical region of the aorta and also in the vitelline artery, to disappear definitively after the 40th day of gestation (Tavian et al., 1999) (Fig. 2).

\section{Morphologic and phenotypic analyses}

Immunohistochemical stainings and hybridizations on embryo sections revealed the primitive nature of these intra-embryonic hematopoietic cells. Indeed, these endothelium-adherent cells exhibit a surface phenotype, which typifies early blood progenitors, being CD45+, CD34+", CD31+, ${ }^{+} D 43^{+}, \mathrm{CD}_{4}{ }^{+}, \mathrm{CD}^{+} 64^{+}$, but CD38- and negative for lineage-specific markers ( Lin $\left.^{-}\right)$. They also express proto-oncogenes and transcription factors (GATA-2, GATA-3, c-myb, SCL/Tal, c-kit) that regulate the initial stages of blood cell development (Labastie et al., 1998, Tavian et al., 1996, Watt et al., 2000).

\section{Functional studies in vitro}

The emergence of these cells within trunk arteries was also correlated with the appearance in that territory of functional hematopoietic progenitors. Indeed, preumbilical trunk tissues dissected from 5-week human embryos and cultured in the presence of MS-5 stromal cells established long-term cultures of hematopoietic cells and produced about 8 times more clonogenic progenitors than liver rudiments at the same stage of development (Tavian et al., 1996).

These results confirmed the existence of a vigorous, precedently unidentified pool of hematopoietic stem cells associated with vascular endothelium in human embryonic truncal arteries.
HSCs associated with vessel walls in the human embryo could be homologous to those present in and underneath the avian embryonic aorta (reviewed in Dieterlen-Lievre, 1994) and within the mouse embryonic aorta/gonads/mesonephros region (GarciaPorrero et al., 1995). However, the possible migration of mouse intra-embryonic HSCs from yolk sac blood islands, rather than their local origin within the embryo, has been a matter of debate and all of our initial investigations were performed at developmental stages when blood already circulates between the yolk sac and embryo (Tavian etal., 1996). It was therefore essential to determine whether embryonic aortic tissues are truly endowed with bloodforming potential.

\section{Hematopoietic potential is present in trunk mesoderm before the aorta develops}

The demonstration of an independent generation of hematopoietic precursor cells inside the human embryo and the comparison of their potential with that of yolk sac-derived cells were performed by virtue of a new in vitro experimental assay (for details see Tavian and Peault, 2005) (Fig. 3). Three-dimensional organ culture of isolated embryonic explants, allowing organ development to proceed in the absence of the rest of the embryo, was carried out. Under these conditions, we have assayed bloodforming potential in the human embryo and yolk sac before and after the 21-day stage of human development, that marks the onset of blood circulation. Successively the splanchnopleura (Sp) - the presumptive region of the hematogenic aorta -, the paraaortic splanchnopleura (P-Sp) and the aorta itself were isolated and maintained in organ culture for 2-4 days, followed by in vitro analyses of hematopoietic potential. The corresponding yolk sac was analyzed under the same conditions in all experiments. From 27 to 40 days of gestation (i.e. stages when intravascular HSC clusters are present), the aorta was expectedly able to establish long-term hematopoietic cell cultures. However, the same potential was observed in the cultures containing the day-19 splanchnopleura, the earliest stage analyzed, at which the aorta has not yet developed. This indicates that 3 days before the onset of blood circulation and one week before the detection of

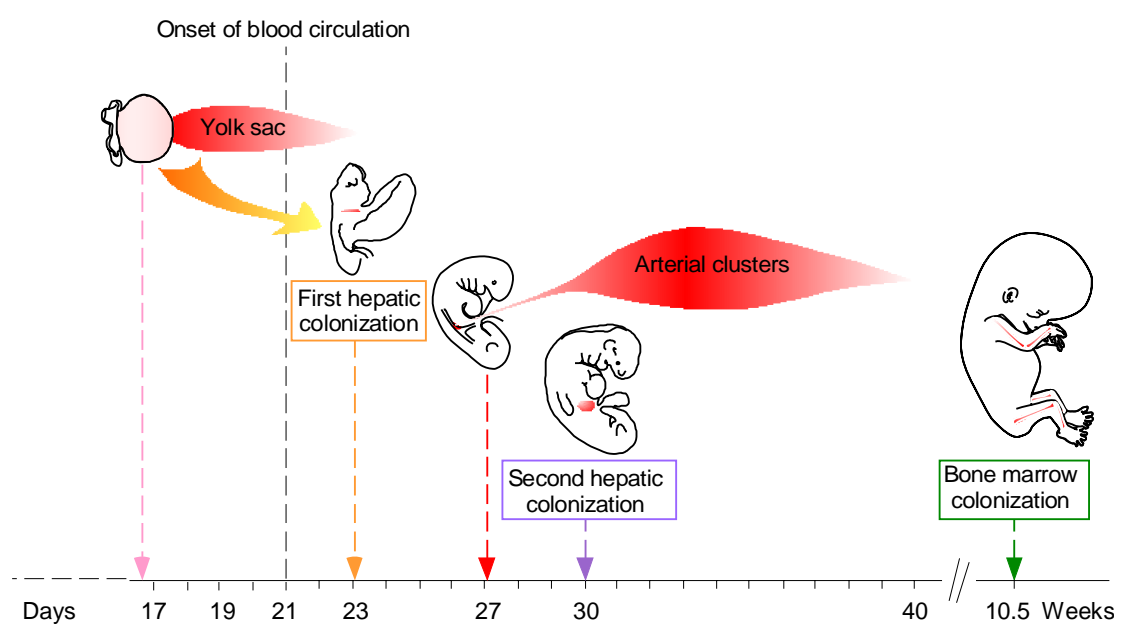

Fig. 4. Chronology of appearance of hematopoietic stem cells in the developing human embryo. 
recognizable HSC clusters in the aorta, the splanchnopleura contains cells already instructed toward hematopoiesis. Therefore, during human development hematopoietic progenitors not only emerge in the yolk sac, but also intrinsically in the embryo proper, from the mesoderm of the splanchnopleura (Tavian et al., 2001).

\section{Comparing the potential of intra-embryonic hematopoietic progenitors with that of yolk sac-derived cells}

Having demonstrated that the intra-embryonic splanchnopleura, that includes the presumptive aorta, is a genuine hematopoietic tissue rudiment, we sought to compare, in terms of lineage potential, hematopoietic cells derived from this site with those originating in the yolk sac. To this end, cells derived from these two independent generation sites were cultured on the MS-5 stromal cell line. This line supports multi-lineage, myelo-lymphoid human hematopoiesis and maintains the T-cell potential that can be assessed by colonizing NOD-SCID mouse fetus thymus rudiments in vitro (Robin et al., 1999a, Robin etal., 1999b). In this setting, a radical difference in differentiation potential was observed between precursors derived from extra- and intra-embryonic compartments (Tavian et al., 2001). Both yolk sac- and embryoderived progenitors yielded myeloid and NK cells. In contrast, only HSCs of intra-embryonic origin also gave rise to T and B cells. These results led to the conclusion that two waves of hematopoietic cell emergence take place in early human ontogeny. The first multipotent, myelo-lymphoid stem cells are generated in the splanchnopleura, within the embryo proper, an observation we have recently confirmed in the model of mice expressing the GFP fluorescent protein under the control of the RAG-1 gene promoter (Yokota et al., publication in preparation). We demonstrate that these HSCs encountered within trunk arteries do stem from the embryo and are not derived from the extra-embryonic yolk sac. These cells are responsible for the second hepatic colonization (Fig. 4) and, therefore, for the establishment of human definitive hematopoiesis (Tavian et al., 2001).

A

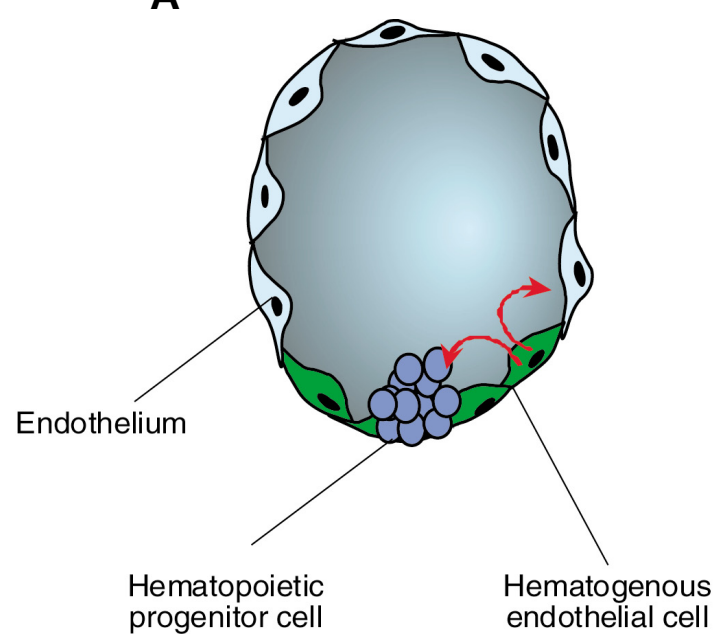

\section{Origin of intra-embryonic hematopoietic progenitors}

The AGM is the region of the embryo that comprises the aorta, genital ridges and mesonephros. The aorta is derived from the splanchnopleura whereas the two latter rudiments originate in paraxial mesoderm, between somites and coelomic cavities. Since the mouse AGM is commonly referred to as the territory where intra-embryonic HSCs originate, we have subdivided the human AGM into its three main components, which have been separately assayed in culture. It was undoubtedly shown that, inside the human embryo, only the aorta is endowed with hematopoietic ability. The gonad and kidney rudiments were in all instances devoid of any detectable blood-forming potential (Tavian et al., 2001). We next searched for the local origin, within the ventral wall of trunk arteries, of emerging hematopoietic stem cells.

\section{Lineage relationship between hematopoietic and endothelial cells}

The yolk sac mesoderm appears to differentiate simultaneously into vascular and hematopoietic structures. Yet the first recognizable blood cells - by either morphology or molecular markers - in the yolk sac are always organized as clusters (or blood islands) that adhere tightly to developing or newly-formed endothelial cells (Murray, 1932, Sabin, 1920). Even more obviously than in the yolk sac, intra-embryonic clusters of HSCs always emerge in close physical association with the differentiated ventral endothelium of trunk blood vessels. These observations set the basis for the hypothesis that endothelial cells themselves are at the origin of embryonic blood cells, which was already suggested a long time ago in the case of yolk sac hematopoiesis (Sabin, 1920). This would imply the re-differentiation of an already organized endothelial cell layer, an event that was indeed recently suggested to be at the origin of intra-embryonic hematopoiesis in mouse and bird embryos (Jaffredo et al., 1998; Nishikawa et al., 1998; de Bruijn et al., 2002 and for review see Dzierzak, 2003).

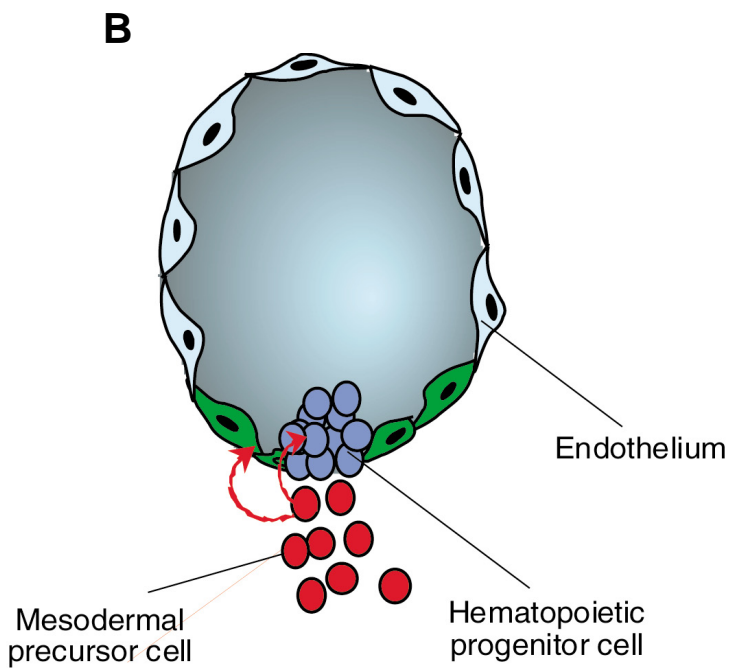

Fig. 5. Models of hematopoietic stem cell emergence within the human embryo. (A) Re-differentiation model. Beginning at 27 days of development, pre-existing endothelial cells (green) in the ventral aspect of human intra-embryonic arteries differentiate locally into blood cell progenitors (blue). (B) Migration model. From 27 days of gestation, scattered mesodermal CD34-CD45-cell precursors (red) colonize the ventral vascular wall and give rise to (blood-forming?) endothelial cells (green) and hematopoietic cell clusters (blue). 
To test this possibility, we have first sorted by flow cytometry vascular endothelial cells from embryonic and fetal human bloodforming tissues. With the exception of CD45, most surface markers expressed on hematopoietic cells (CD31, CD34 and KDR/flk-1) are also present on endothelial cells at these early stages. A reliable marker combination to typify endothelial cells was recognized as CD34 or CD31 surface expression and absence of CD45, which indicates commitment towards hematopoiesis. CD34 ${ }^{+} \mathrm{CD} 45^{-}$sorted cells were devoid of $\mathrm{CD}_{4} 5^{+}$contaminating hematopoietic cells, as assessed by PCR analysis and did not give rise to blood cell colonies when seeded in methyl-cellulose assays. Yet, yolk sac- and AGMderived endothelial cells (days 27-40) differentiated into hematopoietic cells when cultured in the presence of MS-5 stromal cells (Oberlin et al., 2002). The frequency of hematogenous endothelial cells in these organs, at a given stage of ontogeny, was directly correlated with the hematopoietic activity of the tissue they were sorted from. In the yolk sac, where hematopoiesis begins around 16 days of development, the frequency of blood-forming endothelial cells was highest at day 19 , the earliest stage assayed in this study, then decreased rapidly in parallel with the decline of vitelline hematopoiesis. In the whole embryo trunk, the frequency of hematopoiesis-endowed endothelial cells was about $1 / 100$ at day 27 , when HSCs emerge from the floor of the aorta. No hematopoietic activity was detected in cultures of endothelial cells sorted from the AGM region after day 40, when HSCs are no longer present in the lumen of the aorta. These experiments suggested that pre-existing endothelial cells in the human yolk sac and intra-embryonic arteries divide and differentiate locally into blood cell progenitors at the origin of primitive and definitive hematopoiesis (Oberlin et al., 2002).

\section{Conclusion: the ultimate human blood-forming cell}

The main conclusions that can be drawn from the data digested in the present article are that multi-potent hematopoietic stem cells emerge within human embryonic arteries, autonomously from primary vitelline hematopoiesis, through a vascular endothelial cell intermediate. Hemogenicity appears to be acquired secondarily by aortic endothelial cells though. From 24 to 26 days of development, when the AGM is hemogenic in vitro but before the appearance of aortic HSC clusters, cell sorting and culture experiments have revealed that blood-forming potential in the AGM is confined to the CD34-negative, i.e. non-endothelial cell fraction (MT et al., unpublished observations). This suggests either that ventral aortic endothelial cells switch suddenly to hematopoiesis at day 27 , or that more primitive, CD34-angio-hematopoietic progenitors migrate through the peri-aortic mesenchyme and colonize the floor of the aorta at this stage. Several descriptive observations suggest that the latter hypothesis stands true. One is the expression of Flk-1, or VEGF-R2, in the early human embryo, which has revealed that a population of Flk-1+CD34- cells emigrates from the splanchnopleura into the sub-aortic mesoderm during the fourth week of development (Cortes et al., 1999). More recently a surface protein named BB9, expressed in the adult marrow by HSCs and a stromal cell subset (Ramshaw et al., 2001), was detected on a related population of aorta-colonizing cells in the 4-week human embryo. Strikingly, BB9 expression was then retrieved at the surface of both ventral aortic endothelial cells and associated HSCs (Jokubaitis etal., submitted). Hence BB9 may represent the first marker of human angiohematopoietic cells, or hemangioblasts.
We thus speculate that hemangioblasts, or even more primitive mesodermal stem cells migrating from the para-aortic splanchnopleura give rise in the floor of the embryonic aorta to blood-forming endothelial cells and, in turn, hematopoietic stem cells (Fig. 5B). Such differentiation cascades are assumed to be restricted to embryonic and early fetal stages of development. The fact that this may not be the case is implied by recent findings and opens interesting perspectives. Indeed, multipotent stem cells functioning far beyond hematopoiesis have been suggested to exist in adult tissues, among which the bone marrow. We have preliminary evidence that a small fraction of vascular endothelial cells sorted from adult bone marrow cavities can give rise to hematopoietic cells in culture (Souyri et al., unpublished results) and hemangioblasts have been recently claimed to persist in the human adult (Pelosi et al., 2002). It will be interesting to see whether an ancestral mechanism whereby hematopoietic cells are produced from the wall of embryonic blood vessels can be resumed in adult life in situations of emergency.

\section{References}

BAUM, C.M., WEISSMAN, I.L., TSUKAMOTO, A.S., BUCKLE, A.M. and PEAULT, B. (1992). Isolation of a candidate human hematopoietic stem-cell population. Proc Natl Acad Sci USA 89: 2804-8.

BLAZSEK, I., CHAGRAOUI, J. and PEAULT, B. (2000). Ontogenic emergence of the hematon, a morphogenetic stromal unit that supports multipotential hematopoietic progenitors in mouse bone marrow. Blood 96: 3763-71.

BLOOM, W. and BARTELMEZ, G.W. (1940). Hematopoiesis in young human embryos. Am. J. Anat. 67: 21-53.

CHARBORD, P., NEWTON, I., VOILLAT, L., SCHAAL, J.P. and HERVE, P. (1996a). The purification of cd34 cells from human cord blood: Comparison of separation techniques and cytokine requirements for optimal growth of clonogenic progenitors. Br J Haematol 94: 449-54.

CHARBORD, P., TAVIAN, M., HUMEAU, L. and PEAULT, B. (1996b). Early ontogeny of the human marrow from long bones: An immunohistochemical study of hematopoiesis and its microenvironment. Blood 87: 4109-19.

CHOI, K., KENNEDY, M., KAZAROV, A., PAPADIMITRIOU, J.C. and KELLER, G. (1998). A common precursor for hematopoietic and endothelial cells. Development 125: 725-32.

CORTES, F., DEBACKER, C., PEAULT, B. and LABASTIE, M.C. (1999). Differential expression of $\mathrm{kdr} / \mathrm{vegfr}-2$ and $\mathrm{cd} 34$ during mesoderm development of the early human embryo. Mech Dev 83: 161-4.

CUMANO, A., DIETERLEN-LIEVRE, F. and GODIN, I. (1996). Lymphoid potential, probed before circulation in mouse, is restricted to caudal intraembryonic splanchnopleura. Cel/ 86: 907-16.

DE BRUIJN, M.F., MA, X., ROBIN, C., OTTERSBACH, K., SANCHEZ, M.J. and DZIERZAK, E. (2002). Hematopoietic stem cells localize to the endothelial cell layer in the midgestation mouse aorta. Immunity 16: 673-83.

DIETERLEN-LIEVRE, F. (1975). On the origin of haemopoietic stem cells in the avian embryo: An experimental approach. J Embryol Exp Morphol 33: 607-19.

DIETERLEN-LIEVRE, F. (1994). Hemopoiesis during avian ontogeny. Poultry Sci. Rev. 5: 273-305.

DOMMERGUES, M., AUBENY, E., DUMEZ, Y., DURANDY, A. and COULOMBEL, L. (1992). Hematopoiesis in the human yolk sac: Quantitation of erythroid and granulopoietic progenitors between 3.5 and 8 weeks of development. Bone Marrow Transplant 9 Suppl 1:23-7.

DZIERZAK, E. (2003). Ontogenic emergence of definitive hematopoietic stem cells. Curr Opin Hematol 10: 229-34.

EICHMANN, A., CORBEL, C., NATAF, V., VAIGOT, P., BREANT, C. and LE DOUARIN, N.M. (1997). Ligand-dependent development of the endothelial and hemopoietic lineages from embryonic mesodermal cells expressing vascular endothelial growth factor receptor 2. Proc Natl Acad Sci USA 94: 5141-6. 
FUKUDA, T. (1973). Fetal hemopoiesis. I. Electron microscopic studies on human yolk sac hemopoiesis. Virchows Arch B Cell Pathol 14: 197-213.

GARCIA-PORRERO, J.A., GODIN, I.E. and DIETERLEN-LIEVRE, F. (1995). Potential intraembryonic hemogenic sites at pre-liver stages in the mouse. Anat Embryol (Berl) 192: 425-35.

GUILLEMOT, F., TURMEL, P., CHARRON, D., LE DOUARIN, N. and AUFFRAY, C. (1986). Structure, biosynthesis and polymorphism of chicken mhc class ii (bI) antigens and associated molecules. J Immunol 137: 1251-7.

HANN, I.M., BODGER, M.P. and HOFFBRAND, A.V. (1983). Development of pluripotent hematopoietic progenitor cells in the human fetus. Blood 62: 118-23.

HUYHN, A., DOMMERGUES, M., IZAC, B., CROISILLE, L., KATZ, A., VAINCHENKER, W. and COULOMBEL, L. (1995). Characterization of hematopoietic progenitors from human yolk sacs and embryos. Blood 86: 4474-85.

JAFFREDO, T., GAUTIER, R., EICHMANN, A. and DIETERLEN-LIEVRE, F. (1998). Intraaortic hemopoietic cells are derived from endothelial cells during ontogeny. Development 125: 4575-83.

KYOIZUMI, S., MURRAY, L.J. and NAMIKAWA, R. (1993). Preclinical analysis of cytokine therapy in the scid-hu mouse. Blood 81: 1479-88.

LABASTIE, M.C., CORTÉS, F., ROMÉO, P.H., DULAC, C. and PÉAULT, B. (1998). Molecular identity of hematopoietic precursor cells emerging in the human embryo. Blood 92: 3624-3635.

LE DOUARIN, N.M., DIETERLEN-LIEVRE, F. and OLIVER, P.D. (1984). Ontogeny of primary lymphoid organs and lymphoid stem cells. Am J Anat 170: 261-99.

LUCKETT, W.P. (1978). Origin and differentiation of the yolk sac and extraembryonic mesoderm in presomite human and rhesus monkey embryos. Am J Anat 152: 59-97.

MAXIMOV, A.A. (1909). Unterschungen über blut und bindegewebe. I. Die frühesten entwicklungsstadien der bluyt and bindegewebzellen beim säugetier-embryo, bis zum anfang der blutbildung in der leber. Arch. Mikr. Anat. 73: 444-450.

MIGLIACCIO, G., MIGLIACCIO, A.R., PETTI, S., MAVILIO, F., RUSSO, G., LAZZARO, D., TESTA, U., MARINUCCI, M. and PESCHLE, C. (1986). Human embryonic hemopoiesis. Kinetics of progenitors and precursors underlying the yolk sac->liver transition. J. Clin. Invest. 78: 51-60.

MOORE, M.A. and METCALF, D. (1970). Ontogeny of the haemopoietic system: Yolk sac origin of in vivo and in vitro colony forming cells in the developing mouse embryo. British Journal of Haematology 18: 279-96.

MOORE, M.A.S. and OWEN, J.J.T. (1967). Stem cell migration in developing myeloid and lymphoid systems. Lancet 2: 658-659.

MURRAY, P.D.F. (1932). The development «in vitro» of blood of the early chick embryo. Proc. Roy. Soc. London Serie B 111: 497-521.

NISHIKAWA, S.I., NISHIKAWA, S., KAWAMOTO, H., YOSHIDA, H., KIZUMOTO, M., KATAOKA, $\mathrm{H}$. and KATSURA, Y. (1998). In vitro generation of lymphohematopoietic cells from endothelial cells purified from murine embryos. Immunity 8: 761-9.

OBERLIN, E., TAVIAN, M., BLAZSEK, I. and PEAULT, B. (2002). Blood-forming potential of vascular endothelium in the human embryo. Development 129: 4147-57.

PARDANAUD, L., ALTMANN, C., KITOS, P., DIETERLEN-LIEVRE, F. and BUCK, C.A. (1987). Vasculogenesis in the early quail blastodisc as studied with a monoclonal antibody recognizing endothelial cells. Development 100: 339-49.

PEAULT, B. (1987). Mb1, a quail leukocyte/vascular endothelium antigen: Characterization of the lymphocyte-surface form and identification of its secreted counterpart as alpha 2-macroglobulin. Cell Differ 21: 175-87.

PEAULT, B. (1995). Landmarks in the unnatural history of scid-hu mice. In Human hematopoiesis in scid mice, (ed. NAMIKAWA, R. R., M.G. PEAULT, B.). RG Landes Company, Spring-Verlag, Georgetown, TX, USA, pp.3-13.

PEAULT, B., NAMIKAWA, R., KROWKA, J. and MCCUNE, J.M. (1992). Experimental human hematopoiesis in immunodeficient scid mice engrafted with fetal bloodforming organs. In Fetal tissue transplants in medicine, (ed. Edwards, R G.). Cambridge University Press, Cambridge, pp.77-95.
PEAULT, B., WEISSMAN, I.L., BAUM, C., MCCUNE, J.M. and TSUKAMOTO, A (1991). Lymphoid reconstitution of the human fetal thymus in scid mice with cd34+ precursor cells. J Exp Med 174: 1283-6.

PEAULT, B.M., THIERY, J.P. and LE DOUARIN, N.M. (1983). Surface marker for hemopoietic and endothelial cell lineages in quail that is defined by a monoclonal antibody. Proc Natl Acad Sci USA 80: 2976-80.

PELOSI, E., VALTIERI, M., COPPOLA, S., BOTTA, R., GABBIANELLI, M., LULLI, V., MARZIALI, G., MASELLA, B., MULLER, R., SGADARI, C. et al. (2002). Identification of the hemangioblast in postnatal life. Blood 100: 3203-8.

PESCHLE, C., MAVILIO, F., CARE, A., MIGLIACCIO, G., MIGLIACCIO, A.R., SALVO, G., SAMOGGIA, P., PETTI, S., GUERRIERO, R., MARINUCCI, M. et al. (1985). Haemoglobin switching in human embryos: Asynchrony of zeta alpha and epsilon - gamma-globin switches in primitive and definite erythropoietic lineage. Nature 313: 235-8.

PESCHLE, C., MIGLIACCIO, G., LAZZARO, D., PETTI, S., MANCINI, G., CARE, A., RUSSO, G., MASTROBERARDINO, G., MIGLIACCIO, A.R. and TESTA, U. (1984). Hemopoietic development in human embryos. Blood Cells 10: 427-441.

RAMSHAW, H.S., HAYLOCK, D., SWART, B., GRONTHOS, S., HORSFALL, M.J., NIUTTA, S. and SIMMONS, P.J. (2001). Monoclonal antibody bb9 raised against bone marrow stromal cells identifies a cell-surface glycoprotein expressed by primitive human hemopoietic progenitors. Exp Hematol 29: 981-92.

ROBIN, C., BENNACEUR-GRISCELLI, A., LOUACHE, F., VAINCHENKER, W. and COULOMBEL, L. (1999a). Identification of human t-lymphoid progenitor cells in cd34+ cd38low and cd34+ cd38+ subsets of human cord blood and bone marrow cells using nod-scid fetal thymus organ cultures. Br J Haematol 104: 809-19.

ROBIN, C., PFLUMIO, F., VAINCHENKER, W. and COULOMBEL, L. (1999b). Identification of lymphomyeloid primitive progenitor cells in fresh human cord blood and in the marrow of nonobese diabetic-severe combined immunodeficient (nod-scid) mice transplanted with human cd34(+) cord blood cells. J Exp Med 189: $1601-10$

ROSENBERG, M. (1969). Fetal hematopoiesis-case report. Blood 33: 66-78.

SABIN, F.R. (1920). Studies on the origin of blood vessels and of red blood corpuscles as seen in the living blastoderm of chicks during the second day of incubation. Carnegie Inst. Wash. Pub. n²72, Contrib. Embryol. 9: 214-262.

SEVERN, C.B. (1971). A morphological study of the development of the human liver. I. Development of the hepatic diverticulum. Am J Anat 131: 133-58.

TAVIAN, M., COUlOMBEL, L., LUTON, D., CLEMENTE, H.S., DIETERLENLIEVRE, F. and PEAULT, B. (1996). Aorta-associated cd34+ hematopoietic cells in the early human embryo. Blood 87: 67-72.

TAVIAN, M., HALLAIS, M.F. and PEAULT, B. (1999). Emergence of intraembryonic hematopoietic precursors in the pre-liver human embryo. Development 126: 793-803.

TAVIAN, M., ROBIN, C., COULOMBEL, L. and PEAULT, B. (2001). The human embryo, but not its yolk sac, generates lympho-myeloid stem cells: Mapping multipotent hematopoietic cell fate in intraembryonic mesoderm. Immunity 15: 487-95.

TAVIAN, M. and PEAULT, B. (2005). Analysis of hematopoietic development during human embryonic ontogenesis. Methods Mol. Med. 105: 413-24.

UCHIDA, N., YANG, Z., COMBS, J., POURQUIE, O., NGUYEN, M., RAMANATHAN, R., FU, J., WELPLY, A., CHEN, S., WEDDELL, G. et al. (1997). The characterization, molecular cloning and expression of a novel hematopoietic cell antigen from cd34+ human bone marrow cells. Blood 89: 2706-16.

WATT, S.M., BUTLER, L.H., TAVIAN, M., BUHRING, H.J., RAPPOLD, I., SIMMONS, P.J., ZANNETTINO, A.C., BUCK, D., FUCHS, A., DOYONNAS, R. et al. (2000). Functionally defined cd164 epitopes are expressed on cd34(+) cells throughout ontogeny but display distinct distribution patterns in adult hematopoietic and nonhematopoietic tissues. Blood 95: 3113-24.

ZHANG, J., NIU, C., YE, L., HUANG, H., HE, X., TONG, W.G., ROSS, J., HAUG, J., JOHNSON, T., FENG, J.Q. et al. (2003). Identification of the haematopoietic stem cell niche and control of the niche size. Nature 425: 836-41. 